\title{
INNOVATION AND EXTERNAL EVALUATION OF NON-HIGHER EDUCATION SCHOOLS IN PORTUGAL: A STUDY BASED ON EXTERNAL EVALUATION REPORTS
}

\author{
F. Seabra' 1 , S. Henriques ${ }^{2}$, M. Abelha ${ }^{3}$, A. Mouraz ${ }^{4}$ \\ ${ }^{1}$ DEED, LE@D, Universidade Aberta (UAb) / CIEd-UMinho; CIPEM/INET-MD (PORTUGAL) \\ ${ }^{2}$ Iscte - Instituto Universitário de Lisboa / Centro de Investigação e Estudos de Sociologia \\ (cies iscte) e Universidade Aberta (UAb) (PORTUGAL) \\ ${ }^{3}$ CEIS20 - UCoimbra / Universidade Portucalense e Universidade Aberta (UAb) \\ (PORTUGAL) \\ ${ }^{4}$ Universidade Aberta / CIIE-UPorto (PORTUGAL)
}

\begin{abstract}
Processes of educational innovation [1] [2] can be understood as multidimensional processes aiming to answer the complex demands placed by current social dynamics. Responding to this fast-paced changing society, however, has to be a priority of educational systems.

Evaluation and accountability processes have been recognized as essential mechanisms in order to validate innovation - both internally - centered on self-regulation and self-evaluation, - and externally towards the context and society the educational institution answers to. However, external evaluation also carries a number of risks [3], which may lead schools away from innovation, and toward 'safer' choices in terms of a culture of performativity or an audit culture [4] [5] [6].

The current model of External School Evaluation of non-higher education schools in Portugal, which was piloted in 2018, stresses innovative practices, as they are a requirement for schools to achieve the maximum evaluation mention, and less directly since indicators related to innovative practices are included in its referential.

Our communication is based on the documental analysis of the external evaluation reports produced in the current cycle of evaluation and the previous reports on the schools evaluated in this cycle, focusing on innovative practices and intending to answer the following questions: What kinds of practices are deemed as innovative in external evaluation reports? Were there mentions to innovation in those schools' previous reports? How are innovation practices promoted or hindered by the perspectives present in these reports? Fifteen such reports were analyzed by the authors (higher education teachers involved in a project concerned with external school evaluation funded by the Portuguese Foundation for Science and Technology: FCT PTDC/CEDEDG/30410/2017). Results show that there are both positive and negative remarks made about innovative practices in schools. Not all reports refer to innovative practices. Aspects considered innovative are mostly related to the domain «provision of educational service», and to a smaller extent, «leadership and management». Preliminary results show that some «innovative» practices may be reinforced by the external school evaluation reports, regardless of the overall assessment of the schools involved.
\end{abstract}

Keywords: Innovation, External School Evaluation.

\section{INTRODUCTION}

Processes of educational innovation are increasingly becoming a focus for educational research [1][2], and can be understood as multidimensional processes aiming to answer the complex demands placed by current social dynamics, including those derived from the interconnected nature of our societies. The digital revolution we are facing can be perceived as a threat, but also contains in itself opportunity as a drive for change, to foster educational equity [2]. Responding to this fast-paced changing society, however, has to be a priority of educational systems.

In the educational context, and in schools in particular, the concept of innovation has not been exempt from tensions and contradictions. According to Fullan [8], although schools are bombarded with innovations, the new seems to have no place. Kampylis, Bocconi and Punie ([9] p. 7) consider, "educational innovation is not easy to accomplish; in formal education settings, it is often regarded as a highly demanding challenge that usually meets resistance because of its intrinsic complexity". 
Despite its complexity, the OECD/CERI report [10], defines educational innovation as a dynamic change, guided towards adding value to the educational process and leading to measurable results. More recently, another OECD report [2] reinforces that understanding innovation and being able to measure it are key aspects for the improvement of education.

This concern with measurement lead us to consider the importance of evaluation and accountability processes, which have been recognized as essential mechanisms in order to validate innovation - both internally - centered on self-regulation and self-evaluation, - and externally - towards the context and society the educational institution answers to. External school evaluation, in this context, aims to improve the services provided by schools [3]. However, external evaluation also carries a number of risks, such as those described by Ehren and Visscher (in [3] p. 27): ossification, tunnel vision, myopia and measurement fixation, which may lead schools away from innovation, and toward 'safer' choices in terms of a culture of performativity or an audit culture [4] [5] [6].

Thus, the relation between external evaluation and innovation is not linear or free from controversy. Several authors have associated the increase in pressures towards external evaluation policies to movements of concentration of power, standardization of educational models and devaluation of the professional autonomy of school agents, with negative impacts on the creative and emancipatory capacities of the educational communities (Ex. [7]). Any external evaluation model risks producing conformity rather than innovation. Schools may be led to adopt certain practices to comply with legislation on because they were adopted by schools with positive results (isomorphism), either consciously or unconsciously. This may inhibit more innovative strategies to create context-specific solutions, by fear of having negative impacts on evaluation [3].

The program of external evaluation of schools (EES) in Portugal began in 2006 under the responsibility of the General Inspectorate of Education (IGE, currently General Inspectorate of Education and Science, IGEC), assuming as its main objectives to promote a culture and practice of evaluation of the education and training system and to improve the quality of teaching and learning. The implementation of the first cycle of EES took place between 2007 and 2011 and considered five domains of analysis: Results, Provision of Educational Service, School Organization and Management, Leadership, and Capacity for self-regulation and Improvement. Each of these domains includes several factors and innovation was referred to in this referential associated to the domain Leadership, specifically in the factor «openness to innovation», which included 2 referents: openness to innovation and innovative solutions [11] [12].

The $2^{\text {nd }}$ cycle of EES (2011-2017) would use a new frame of reference, structured in 3 domains: Results, Provision of Educational Service and Leadership and Management, each also subdivided in fields of analysis and specified in referents [13] [14]. In this cycle, the idea of innovation was integrated in the appreciation of projects, included in the domain Leadership and Management, specifically the subdomain of Leadership. This item required the evaluation team to appreciate the "development of projects, partnerships and innovative solutions".

The $3^{\text {rd }}$ cycle of EES would begin in 2018, also conducted by the IGEC. The frame of reference would maintain the previous three domains - Results, Provision of Educational Service and Leadership and Management - adding a $4^{\text {th }}$ domain, which would address Self-evaluation separately [15]. Innovation is featured in this frame of reference as part of the domain «Provision of Educational Service», specifically in the field of analysis «Educational offers and curricular management», and the referent «Curricular innovation», stressing curricular and pedagogical innovation. Furthermore, and for the first time, innovation is included in the descriptors for the levels of evaluation, and innovative practices are a requirement for schools to achieve the maximum evaluation mention.

The present article considers EES as a process with potential impact on innovation at several levels and dimensions of the schools' organization and educational action, and is integrated in a wider project «Mechanisms of change in schools and the inspectorate. A study on the $3^{\text {rd }}$ cycle of External Evaluation of non-higher education Schools in Portugal", funded by the national Foundation for Science and Technology (FCT PTDC/CEDEDG/30410/2017), aiming to know the formal and informal mechanisms for change.

\section{METHODOLOGY}

A documental analysis was carried out, on the External Evaluation Reports of Non-higher Education Schools in Portugal available at the date of data gathering (February 2020), specifically 9 reports of the pilot phase of implementation of the $3^{\text {rd }}$ cycle of External Evaluation (2017-2018) and 6 reports pertaining 
the evaluations performed in the academic year of 2018/2019. These reports are public, and were obtained from the website of the General Inspectorate of Education and Science ${ }^{1}$.

Whenever possible, previous reports of those same schools were also analyzed. This was not always the case, as the $3^{\text {rd }}$ cycle of EES included, for the first time, several categories of schools: schools of integrated artistic teaching; professional schools; Private and cooperative schools with a contract of association or sponsorship and those whose revenue is mostly derived from public funding; and other private and cooperative schools, per their request.

Among the 15 schools evaluated in this cycle and with public reports at the date of data gathering, 8 had never been subject to EES before, and therefore, only 7 schools had previous reports available. Among these, one of the schools did not have reports from all 3 cycles (due to reorganizations of the school clusters) and was therefore excluded from analysis.

The analysis of reports focused on information which would assist in answering the research questions previously presented in this paper.

Firstly, a quantitative analysis of the results of the schools was carried out. This was followed by a quantitative analysis of the mentions to innovative practices in the body of the report and particularly in the fields "Strong features» and «Areas for improvement». We then proceeded to a qualitative analysis of the content of such references. Lastly, we compared these mentions to those present in previous reports of the same schools.

Schools were identified by codes, where P\# refers to the schools evaluated during the pilot year of the $3^{\text {rd }}$ cycle of ESE, and S\# refers to schools evaluated in the year 2018/2019.

\section{RESULTS}

\subsection{Quantitative Results}

In this section, we present the quantitative results of the content analysis, considering the qualitative mentions obtained by the schools under analysis. An average classification was derived, using the following correspondence between qualitative scale and quantitative scale: the mention of excellent was translated as 5 points, very good as 4 points, good as 3 points, sufficient as 2 points and insufficient as 1 point. The results are shown in table 1.

Table 1. Classifications obtained by the schools under analysis

\begin{tabular}{c|c|c|c|c|c}
\hline \hline Schools & Self-Evaluation & $\begin{array}{c}\text { Leadership and } \\
\text { Management }\end{array}$ & $\begin{array}{c}\text { Provision of } \\
\text { Educational } \\
\text { Service }\end{array}$ & Results & $\begin{array}{c}\text { Average } \\
\text { "Classification» }\end{array}$ \\
\hline P1 & Very Good & Very Good & Good & Good & 3,5 \\
\hline P2 & Sufficient & Very Good & Very Good & Very Good & 3,5 \\
\hline P3 & Very Good & Very Good & Good & Good & 3,5 \\
\hline P4 & Good & Very Good & Good & Very Good & 3,5 \\
\hline P5 & Very Good & Very Good & Very Good & Good & 3,75 \\
\hline P6 & Very Good & Excellent & Excellent & Excellent & 4,75 \\
\hline P7 & Good & Very Good & Good & Very Good & 3,5 \\
\hline P8 & Sufficient & Sufficient & Sufficient & Good & 2,25 \\
\hline P9 & Insufficient & Good & Good & Good & 2,5 \\
\hline S1 & Good & Good & Good & Good & 3 \\
\hline S2 & Sufficient & Very Good & Good & Good & 3 \\
\hline S3 & Good & Very Good & Very Good & Very Good & 3,75 \\
\hline S4 & Sufficient & Good & Good & Good & 2,75 \\
\hline S5 & Sufficient & Good & Sufficient & Good & 2,5 \\
\hline S6 & Sufficient & Good & Good & Good & 2,75 \\
\hline \hline
\end{tabular}

Next, we proceeded to juxtapose the average classifications obtained by each school, with the number of mentions to innovation included in their $3^{\text {rd }}$ cycle reports, as presented in table 2. Positive and negative

\footnotetext{
${ }^{1}$ https://www.igec.mec.pt/PgMapa.htm
} 
references (ex.: practice considered not to be innovative) are counted separately. Interrogated numbers refer to mentions to innovation which are dubious. More information on the content of those remarks is presented in the next section, pertaining qualitative results.

Table 2. Mentions to innovative practices in reports by field of analysis

\begin{tabular}{|c|c|c|c|c|c|c|c|c|}
\hline Schools & $\begin{array}{c}\text { Average } \\
\text { "Classificat } \\
\text { ion» }\end{array}$ & $\begin{array}{c}\text { Self- } \\
\text { Evaluation }\end{array}$ & $\begin{array}{l}\text { Leadership } \\
\text { and } \\
\text { Management }\end{array}$ & $\begin{array}{c}\text { Provision } \\
\text { of } \\
\text { Educational } \\
\text { Service }\end{array}$ & Results & $\begin{array}{c}\text { Strong } \\
\text { features }\end{array}$ & $\begin{array}{c}\text { Areas for } \\
\text { improvem } \\
\text { ent }\end{array}$ & Total \\
\hline $\mathrm{P} 1$ & 3,5 & & 1 & 1 & & 1 & & 3 \\
\hline $\mathrm{P} 2$ & 3,5 & & & & & & & 0 \\
\hline P3 & 3,5 & & & 1 & & & & 1 \\
\hline P4 & 3,5 & & $1 ?$ & $1 /-1$ & & 1 & & $1 ? / 2 /-1$ \\
\hline P5 & 3,75 & & $1 ?$ & 2 & & & & $1 ? / 2$ \\
\hline P6 & 4,75 & & $1 ?$ & 2 & 2 & & & $1 ? / 4$ \\
\hline P7 & 3,5 & & & & & & & 0 \\
\hline P8 & 2,25 & & & $1 ? / 1$ & & & & $1 ? / 1$ \\
\hline P9 & 2,5 & & & & & & & 0 \\
\hline $\mathrm{S} 1$ & 3 & & 1 & $1 /-1$ & & & & $2 /-1$ \\
\hline S2 & 3 & & & $1 ?$ & & & & $1 ?$ \\
\hline S3 & 3,75 & & & & & & & 0 \\
\hline S4 & 2,75 & & -1 & -1 & & & -1 & -3 \\
\hline S5 & 2,5 & & & & & & & 0 \\
\hline S6 & 2,75 & & 1 & 1 & & 2 & & 4 \\
\hline
\end{tabular}

These results show the following tendencies, which we consider noteworthy:

A total of 5 schools' reports did not include any mention to innovation. Among those are schools with good classifications (such as S3, with one of the highest average classification - 3,75) as well as 2 schools among those with the lowest classifications (P9 and S5, with an average of 2,5). Looking specifically at results obtained by those schools on the domain «Provision of Educational Service» which is the most closely related to the innovation throughout the reports - results of these schools range from Sufficient to Very Good. Surprisingly, even schools with negative remarks concerning innovation (P4 with an average of 3,5, a report which also includes positive remarks; S1, average of 3 points, and S4, average of 2,75 and three negative remarks concerning innovation) are not always among the ones with the lowest scores, although when looking closer at the scores on the domain «Provision of Educational Service» all three schools with negative remarks on innovation had a qualitative appraisal of «Good». The acknowledgment of innovative practices in schools by the evaluation committees does therefore seem not to have been a key aspect for attributing good appraisals of the work carried out.

However, the only school which received several (or any) mentions of Excellent performance is also the one with more frequent references to innovation registered on the report. This is consistent with the description of each qualitative mention, as the attribution of Excellent requires the presence of «innovative practices» [16].

Considering the distribution of the references to innovation by domains of analysis, the field «Provision of Educational Service» stands out as the one with more references, across the reports under analysis, with 10 positive mentions, 2 ambiguous and 3 negative mentions. The domain «Leadership and Management» follows suit, with 3 positive mentions, 3 dubious mentions and 1 negative mention. Only one school's report - that of P6, the school with the best results - includes mentions to innovation in the domain of «Results», and none of the reports includes mentions to innovation in the field of "SelfEvaluation».

Looking in particular to the summary fields of «Strong Features» and «Areas for Improvement», which are particularly relevant as they include the aspects deemed most salient in the report, 3 reports referred to innovation as a strong feature (P1 and P4 with average results of 3,5 and $\mathrm{S} 6$ - average result of 2,75 ) 
and only 1 report ( $S 4$ - average of 2,75 ) included a mention to innovation as an area for improvement. This further reinforces the lack of correspondence between good results as a whole and the acknowledgement of innovative practices in reports.

\subsection{Qualitative Results}

In this section, we present the qualitative results of the content analysis, looking into the actual content of the mentions previously quantified. What precisely is considered innovative by the external evaluators?

\subsubsection{Leadership and Management}

Looking closer into the domain «Leadership and Management», aspects related to projects, partnerships and pedagogical practices, including those that use educational technologies or experimental practices, were deemed innovative:

P1 - The report refers to local, national and international projects carried out by this school, ranging from practices related to entrepreneurship, to international exchanges among others, to partnerships with several institutions and to "innovative solutions (ex. Experimental sciences in preschool education (...) initiation to programming and robotics club) with impact on the improvement of the provision of the educational service" (p. 4).

$S 1$ - The report refers to the undertaking of "multiple initiatives that promote the diversification of learning experiences" (p. 7), naming projects, contests, and programs at the European level.

S6 - The report has 2 separate mentions, one to "multiple projects, activities and innovative solutions" (p.7), to the establishment of partnerships and protocols and mobilize resources, in order to improve the educational service. The second mention names specific projects using technologies and innovative teaching techniques.

Among the ambiguous mentions to innovative practices in this field of analysis are more general references to openness to change (P5, P6) and one mention to projects which are considered improvements to educational practices but are not considered truly innovative (P4).

Lastly, the negative references to innovation focus on the absence of new projects and lack of innovation in terms of pedagogical solutions (S4).

S4 - The report states that "There are no visible recent measures, transversal to the organization (...) aiming for the creation of innovative projects and the search for new pedagogical solutions"

\subsubsection{Provision of Educational Service}

As previously mentioned, this is the domain within which most of the references to innovation were made in the reports, which is not surprising, when taking into account that the reports include a sub topic named "educational proposal and pedagogical innovation" in this field.

Positive references to innovation are frequently linked to curriculum, whether through specific changes made within the Project of Curricular Autonomy and Flexibility, or with the creation of specific professional courses. These innovations cross multiple curricular and extra-curricular areas and activities, related not only to technology, digital literacy, and experimental sciences, as might be expected, but also with arts or personal development. Ambiguous remarks are made in two of these schools, as innovation is considered localized in specific activities or projects, rather than affecting the school as a whole.

$\mathrm{P} 1$ - refers to the curricular proposal of the school, considered innovative at the levels of complementary offers (Ex. Initiation to programming, experimental sciences, introduction to classical culture and languages), school offers, and projects and clubs, which are considered "relevant for the children's scientific, cultural and civic upbringing" (p.6).

P3 - The school volunteered for the project of Curricular Autonomy and Flexibility, and therefore is considered to seek innovation in curriculum management. There is reference to a professional course, as well as to the mandatory frequency of artistic areas in certain curricular years, which "contribute to foster work habits and improve students' attitudes towards the school" (p. 7).

P4 - There is reference to projects "with features of curricular and pedagogical innovation", related to the project of Curricular Flexibility and Autonomy, including a complementary school level curricular 
offer, the use of active methodologies and inter-disciplinarity, projects and collaborative practices among teachers and students.

P5 - Two remarks were made in this report, one focusing on the Project of Curricular Autonomy and Flexibility, stressing projects, experimental science activities, robotics, among other initiatives related to the environment, arts and sports; and another on the "openness and determination to initiate pathways of change, though circumscribed, signaling the emergence/renovation of teaching practices" (p.8).

P6 - Again there are 2 remarks on innovation, one focusing on the effective diagnosis of needs leading to curricular innovations, and another on the personal development and well-being of the children and students "responsibility, citizenship, demand, discipline, participation, resiliency, search for excellency, innovative spirit" among others (p.7).

P8 - This report includes 1 ambiguous remark, referring to innovative practices, which are "circumscribed to the involvement of a restricted number of teachers and classes" (p.7), and 1 positive remark stressing curricular innovation and contextualization, particularly within a specific professional course.

S1 - Innovative pedagogical practices were observed in relation to a specific project.

S2 - Ambiguous remark: Practices seeking to innovate processes of teaching and learning are registered, although they are not considered to affect the school broadly.

S6 - The report stresses "an intentional incidence, in terms of curricular and pedagogical innovation, in the development of digital literacy and in approaches which involve students in practices of support to learning which foster creativity" (p.8).

The negative remarks to innovation in this field refer to the absence of curricular $(\mathrm{S} 1, \mathrm{~S} 4)$ or pedagogical innovation (P4).

P4 - The presence of several initiatives which are considered innovative is "in contrast, however, with practices of transmissive matrix, oriented towards success in the national tests and exams, particularly in secondary education" (p.6).

S1 - The presence of innovation at the level of curricular options was not considered evident.

S4 - The report clearly states the absence of relevant initiatives of curricular innovation.

\subsubsection{Results}

Only 1 school's report evidenced any reference to innovation in the domain of results. This report contains 2 mentions, one to academic results, and another to social results. Concretely, related to academic results, innovation is related to the work conducted by the school to achieve inclusivity of all students, including those with some kind of impairment. The mention to social results focuses on the participation of students' association, involved in the conception, planning and implementation of innovative initiatives "allowing the development of very diversified competences".

\subsubsection{Strong Features and Areas for Improvement}

As previously detailed, 3 reports include mentions to innovation among the Strong Features identified in schools.

P1 - The report mentions innovation as a strength related to the domain «Management and Leadership», stressing the "action by leaderships in promoting projects, partnerships and innovative solutions", although this is framed as having a "positive impact on the learnings and experiences of children and students" (p.10).

P4 - In this case, the strength is identified as pertaining the "Provision of Educational Service» and focuses on "the projects undertaken, with features of curricular and pedagogical innovation", once again, related to the quality of learning (p.11).

S6 - Again, the strength is located at the level of «Provision of Educational Service» and focuses on "Curricular and pedagogical innovation approaches, which involve student in activities combining different knowledge and promote the development of creativity and of digital literacy" (p.4).

One report included a mention to innovation as an area for improvement (S4). This area was identified in relation to the domain «Leadership and Management», and suggests the "Conception of transversal to the organization, explicit and differentiating measures aiming the creation of innovative projects and 
the search for new pedagogical solutions" (p.5). As expressed, this need for improvement is directed at the leaders' capacity to promote innovation, however, the lack of innovation in itself is located at the level of projects and pedagogical practices.

In this section, innovative practices (or lack thereof) are deemed primarily, either as a responsibility of leaderships, or as a feature of pedagogical and curricular practices and are related closely to the experiences and learning opportunities made available to students.

\subsection{Looking at past reports}

As previously mentioned the idea of innovation was already featured in the previous cycles of EES, as an aspect to consider within the domain "Leadership» ( $1^{\text {st }}$ cycle) associated with openness to innovation and innovative solutions, and "Leadership and Management» ( $2^{\text {nd }}$ cycle), associated to innovative projects, partnerships and solutions.

Looking into previous appreciations that the EES reports have made of each of the schools which have previously been subject to this process and identifying the number of times the noun «innovation» (or its derivations as a verb or adjective) are counted, can be resumed in the following table (Table 3).

Table 3. References to innovation in schools previously subjected to EES

\begin{tabular}{|c|c|c|c|c|c|c|c|c|}
\hline $\begin{array}{l}\frac{n}{\delta} \\
\stackrel{\vdots}{\delta} \\
\dot{s}\end{array}$ & 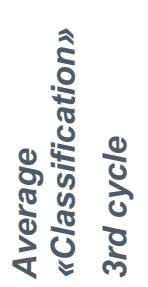 & 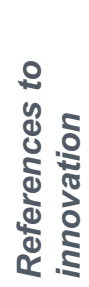 & 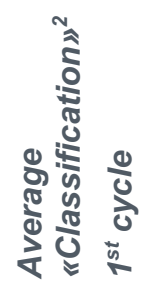 & 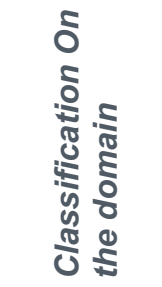 & 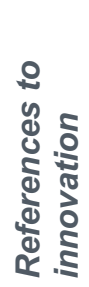 & 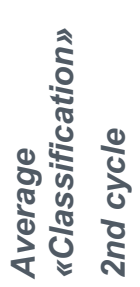 & 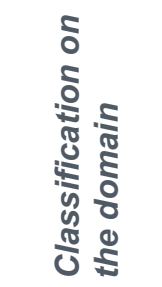 & 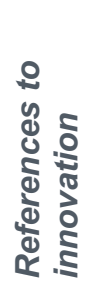 \\
\hline $\mathrm{P} 1$ & 3,5 & 3 & 2,4 & Good & 3 & 3,66 & Very Good & 0 \\
\hline P3 & 3,5 & 1 & 2,4 & Sufficient & 4 & 3 & Good & 0 \\
\hline P5 & 3,75 & $1 ? / 2$ & 4 & Very Good & 4 & 4 & Very Good & 2 \\
\hline P8 & 2,25 & $1 ? / 1$ & 3,1 & Very Good & 3 & 3 & Good & 0 \\
\hline S3 & 3,75 & 0 & 3 & Good & 4 & 4 & Very Good & 2 \\
\hline S6 & 2,75 & 4 & 3 & Good & 2 & 3 & Good & 0 \\
\hline
\end{tabular}

A first analysis of the table allows us to point out that the number of references to the word innovation in the 1st cycle does not appear to be related to the presence of innovative activities at schools, but simply to the mention of this word in the descriptors. Differently, in the $2^{\text {nd }}$ cycle, the two schools with reports mentioning innovation are also the ones which were classified as Very Good in the domain under analysis, and remained the ones with better overall scores in the $3^{\text {rd }}$ cycle of EES, among those included in the retrospective analysis.

The number of references to innovation seems to have increased from the $2^{\text {nd }}$ to the $3^{\text {rd }}$ cycles of EES, signaling greater focus on this concept.

In terms of content, the reports on school P1 mentioned the development of innovative projects in the $1^{\text {st }}$ cycle, and the $2^{\text {nd }}$ cycle maintains reference to projects in the areas of science, communication, sports, and political intervention, not referenced as innovative.

P3 is referenced as being receptive to change and development of innovative projects, although some attempts of innovation are considered ineffective. In the $2^{\text {nd }}$ cycle there is reference to participation in national and international projects, also not labeled as innovative.

P5 is considered open to innovation and an active space for the dissemination and creation of culture and science, which is related to participation in multiple projects $\left(1^{\text {st }}\right.$ cycle); in the $2^{\text {nd }}$ cycle there is reference to innovative problem solving, as leaderships mobilize resources in order to prosecute innovative projects in diverse areas.

\footnotetext{
${ }^{2}$ In the 1 st cycle of EES classifications were expressed in only four qualitative mentions: Insufficient, Sufficient, Good and Very Good.
} 
P8 is also considered open to innovation and change in the 1st cycle of EES, proof of that being the multiple projects it is involved in and prizes one in the area of exact sciences; in the $2^{\text {nd }}$ cycle references to projects remain, but not being deemed innovative.

S3 is considered open and capable of change, stressing the adhesion to projects and contests $\left(1^{\text {st }}\right.$ cycle). In the $2^{\text {nd }}$ cycle innovation is pointed out as a strong feature of the school, related to openness to innovation, and the development of projects, stressing those related to science.

S6 refers to openness to chance by the management organ, which is not accompanied by intermediate leaderships ( $1^{\text {st }}$ cycle); in the $2^{\text {nd }}$ cycle there is no reference to innovation.

From the qualitative analysis of the references present in the EES reports concerning the $1^{\text {st }}$ and $2^{\text {nd }}$ cycles two tendencies emerge as differentiating what is considered as innovation of the schools' educational action: the first is relative to the promotion of innovative projects, oriented towards the improvement of students' learning. Such projects are frequently associated to the promotion of scientific literacies or to culture in general, and in the $2^{\text {nd }}$ cycle of EES there are more frequent references to international projects the schools are involved in.

The second tendency that seems to mark the evaluation made by the IGEC, and which is associated with the attribution of good results in the respective domain, is the acknowledgment of a school climate characterized by openness to change, which seems to endure in time.

\section{CONCLUSIONS}

Looking again at the results presented, we now intend to attempt to shed light on the questions which guided our analysis.

What kinds of practices are deemed as innovative in external evaluation reports?

It appears that a shift can be noticed in the kinds of practices which have been deemed as innovative, across the 3 cycles of EES, accompanying what is proposed by the frames of reference that have guided EES in those cycles. In the first two cycles of EES innovation was allocated as a responsibility of leaderships, and closely related to a rather general feeling of «openness to change» ( $1^{\text {st }}$ cycle), and more concretely and measurably to the adhesion to projects, partnerships and innovative solutions $\left(2^{\text {nd }}\right.$ cycle). References to this culture or climate of openness to change have carried on across all cycles of EES, as have references to projects and partnerships. However, the $3^{\text {rd }}$ cycle of EES allocated the descriptors related to innovation to the domain of «Provision of Educational Service», promoting a focus on the curricular and pedagogical aspects of innovation. Thus, references to innovative practices in the $3^{\text {rd }}$ cycle reveal the centrality of curriculum and pedagogy, which is coherent with changes in legislation allowing schools greater margin in terms of curricular autonomy and flexibility that are contemporaneously under application.

Currently, and although a general ambience of openness to innovation as well as references to projects and partnerships (considered to have an impact on students' learning) remain prevalent, most references to innovation pertain curricular innovation, associated with the creation of professional courses, to school offers, and original ways of organizing curriculum. References to innovation in the domain of Leadership also remain frequent, signalling a potential culture of evaluation which has been developing over the years, as well as the recognition that curricular and pedagogical innovation also requires or is promoted by open and flexible leaderships paving the way for teachers' action.

It is noteworthy that initiatives deemed innovative have not been exclusively related to the most «traditional» fields of science and technology, but encompass a variety of fields, including the arts, culture and even civic concerns.

Were there previous mentions to innovation in those schools previous reports?

When it was possible to look retrospectively at the reports of the schools analysed in the $3^{\text {rd }}$ cycle of EES (6 schools), we find a relative inconsistency in the number of references to innovation across cycles. The number of mentions was high across schools for the $1^{\text {st }}$ cycle, but this seems to reflect the reference to the names of themes under analysis rather than the actual verification of innovative practices. In the $2^{\text {nd }}$ cycle, however, the schools considered to have innovative practices, associated with several projects and concrete initiatives, were also the ones which obtained the best classifications in the domain under analysis and remain well evaluated as a whole in the $3^{\text {rd }}$ cycle. We may hypothesize that in schools where these «innovative» practices were already well established, this openness to innovation may have also been present in terms of curricular and pedagogical innovation. 
How are innovation practiced promoted or hindered by the perspectives present in these reports?

It appears that between the $1^{\text {st }}$ and the $2^{\text {nd }}$ cycle, the frame of reference narrowed in scope, becoming more focused on measurable instances of innovation. This might represent a risk of narrowing schools' options to initiatives which would be easily documented and would allow them to easily «check the innovation box» in this frame of reference. The increased salience of innovation in the frame of reference of the $3^{\text {rd }}$ cycle of ESE would increase this peril, if it were not for the fact that the focus seems to have shifted from adhesion to projects to the promotion of innovative curricular and pedagogical practices. Only in time, and accompanying the development of the EES project over the $3^{\text {rd }}$ cycle may we question if schools are attempting to copy the curricular and pedagogical actions of the schools with good results.

On the other hand, the relative independence that seems to exist between the verification of practices considered innovative by the EES and the overall classification of the schools - with exclusion of the very best mention (Excellent) which requires this verification - may relieve pressure from schools in terms of a possible pressure to «innovate or perish». This remains an unanswered question, to a great extent, and will require further investigation.

\section{ACKNOWLEDGEMENTS}

This paper is supported by the Foundation for Science and Technology (Portugal), under the project FCT PTDC/CEDEDG/30410/2017.

\section{REFERENCES}

[1] S. J. Ball, and C. Juneman, Networks, New Governance and Education. Bristol: The Policy Press, 2012.

[2] S. Vincent-Lancrin, J. Urgel, S. Kar and G. Jacotin Measuring Innovation in Education 2019: What Has Changed in the Classroom?, Educational Research and Innovation. Paris: OECD, 2019.

[3] J. A. Pacheco, F. Seabra and J. C. Morgado, "Avaliação Externa. Para a referencialização de um quadro teórico sobre o impacto e os efeitos nas escolas do enino não superior" In Avaliação Externa de Escolas: Quadro Teórico/Conceptual (J. A. Pacheco, Org.), pp. 15-55, Porto/Portugal: Porto Editora, 2014.

[4] S. J. Ball, "The teacher's soul and the terrors of performativity", Journal of Education Policy, Vol. 18, no 2, pp. 215-228, 2003.

[5] C. Shore, C., "Audit culture and illiberal governance: Universities and politics of accountability", Anthropological Theory, Vol. 8, no 3, pp. 278-298, 2008.

[6] A. Falabella, A., "The Performing School: The effects of market and accountability policies". Educational Policy Analysis Archives, Vol. 22, no 70, pp. 1-28, 2014.

[7] Lima, L. and Afonso, A., Reformas da educação pública. Democratização, modernização, neoliberalismo. Porto: Edições Afrontamento, 2002.

[8] M. Fullan, El Cambio educativo: guía de planeación para maestros. México: Trilhas, 2000.

[9] P. Kampylis, S. Bocconi, and Y Punie, Towards a Mapping Framework of ICT-enabled Innovation for Learning. Luxembourg: Publications Office of the European Union, European Commission-Joint Research Center, 2012.

[10] H. Dumont, D. Istance, D., and F. Benavides (Eds), The Nature of Learning: Using Research to Inspire Practice. Paris: OECD - CERI, 2010.

[11] Inspeção Geral de Educação (IGE). Primeiro Ciclo de Avaliação Externa de Escolas: documentos de enquadramento (2006-2011), Lisbon/Portugal: IGE, 2006.

[12] Inspeção Geral da Educação (IGE). Avaliação Externa das Escolas 2007-2008 - Relatório. Lisbon/Portugal: IGE, 2009.

[13] Inspeção Geral de Educação e Ciência (IGEC). Segundo Ciclo de Avaliação Externa de Escolas: documentos de enquadramento (2011-2017), Lisbon/Portugal: IGEC, 2011.

[14] Inspeção Geral de Educação e Ciência (IGEC). Avaliação Externa das Escolas 2012-2013 Relatório. Lisbon/Portugal: IGEC, 2015. 
[15] Inspeção Geral de Educação e Ciência (IGEC). Terceiro Ciclo de Avaliação Externa de Escolas: documentos de enquadramento (2018-2019). Lisbon/Portugal: IGEC, 2019.

[16] Inspeção Geral de Educação e Ciência (IGEC). Terceiro Ciclo de Avaliação Externa de Escolas. Escala de Avaliação. Lisbon/Portugal: IGEC, 2019. 